RU Формирование коммуникативных умений обучающихся с использованием видеоматериалов на уроках русского языка

\author{
Олесова А. П., Бурцева Д. Р.
}

\begin{abstract}
Аннотащия. Цель исследования - разработать комплекс методических приемов на основе использования видеоматериалов для формирования коммуникативных умений обучающихся на уроках русского языка. В статье рассматриваются дефиниции и классификации коммуникативных умений, аудиовизуальных средств обучения, в частности видеоматериалов, их дидактический потенциал для активизации речевой деятельности обучающихся. Научная новизна заключается в том, что определены пути совершенствования работы по развитию устной монологической, диалогической, письменной связной речи школьников с привлечением видеоматериалов в процессе обучения русскому языку. В результате дано авторское определение коммуникативных умений, представлена поэтапная работа с видеоматериалами (социальные ролики, ролики с фрагментами из художественных фильмов) с использованием предлагаемого комплекса методических приемов в целях формирования коммуникативных умений обучающихся на уроках русского языка.
\end{abstract}

\title{
EN Formation of Students' Communication Skills Using Video Materials during Russian Classes
}

\author{
Olesova A. P., Burtseva D. R.
}

\begin{abstract}
The purpose of the study is to produce a set of methodological techniques based on the use of video materials to form students' communication skills during Russian classes. The article considers definitions and classifications of communication skills, audio-visual teaching tools, in particular video materials, their didactic potential for activating students' speech activity. Scientific novelty of the study lies in the fact that the researchers have identified ways of improving work on development of schoolchildren's oral monologic, dialogic, written coherent speech with involvement of video materials in the process of teaching Russian. As a result, an author's definition of communication skills is given, step-by-step work with video materials (public service announcements, feature film clips) using the proposed set of methodological techniques in order to form students' communication skills during Russian classes is presented.
\end{abstract}

\section{Введение}

Актуальность исследования обусловлена задачами, стоящими перед современной школой, и непреходящей значимостью в лингвометодике проблемы формирования коммуникативных умений обучающихся. Одной из приоритетных задач школы является подготовка обучающихся к дальнейшей социализации, успешность которой во многом зависит от коммуникативных умений, готовности к взаимодействию и продуктивному общению как в устной, так и в письменной форме. Сформированные умения принимать участие в диалоге, аргументировать свою позицию, критически оценивать и интерпретировать информацию, полученную из различных источников, зафиксированы в Федеральном государственном образовательном стандарте как метапредметные результаты обучения в школе [22]. В связи с этим следует отметить, что целенаправленная системная работа по формированию коммуникативных умений осуществляется именно в процессе обучения русскому языку, а овладение обучающимися коммуникативной компетенцией является главной практической целью обучения русскому языку и проверяется на государственной итоговой аттестации школьников в 9 и 11 классах.

В методике русского языка концептуальные положения системы обучения видам речевой деятельности, формирования коммуникативных умений изложены в трудах таких известных ученых, как Е. С. Антонова [3], Т. М. Воителева [6], Н. А. Ипполитова [9], Т. А. Ладыженская [19], М. Р. Львов [14], В. Н. Мещеряков [15]. 
Сегодня, когда информационно-коммуникационные технологии (далее - ИКТ) широко внедряются в образовательный процесс, особый интерес представляет использование аудиовизуальных средств обучения, в частности видеоматериалов, для формирования коммуникативных умений обучающихся. Эта проблема активно разрабатывается в методике преподавания иностранных языков, в том числе РКИ, и нашла отражение в исследованиях М. П. Алексеевой [1], Ю. В. Кохендерфер [12], О. В. Хурмуз [24], А. Н. Щукина [26] и многих других.

Привлечение видеоматериалов для формирования коммуникативных умений школьников в процессе обучения русскому (родному) языку рассматривается в работе О. Б. Афанасенко [4], упоминается в отдельных научно-методических статьях, например, Е. В. Шарун [25], и требует дальнейшего изучения.

Данное обстоятельство обусловило выбор предмета и цель нашего исследования, достижение которой потребовало решения ряда задач:

- на основе изучения специальной литературы по исследуемой проблеме рассмотреть дефиниции и классификации коммуникативных умений;

- охарактеризовать аудиовизуальные средства обучения и виды видеоматериалов;

- определить основные положения по использованию комплекса методических приемов работы с видеоматериалами для формирования коммуникативных умений обучающихся на уроках русского языка.

Для этого в ходе исследования использовались следующие методы: теоретический (анализ литературы), теоретико-эмпирический (изучение и обобщение педагогического опыта, моделирование комплекса методических приемов).

Теоретической базой исследования явились теория речевой деятельности (Л. С. Выготский [7], Н. И. Жинкин [8], А. А. Леонтьев [13] и др.), основные положения методики развития связной речи (Е. С. Антонова [3], Т. М. Воителева [6], Т. А. Ладыженская [19] и др.), классификации аудиовизуальных средств обучения в общей дидактике, а также в лингвометодике (Г. М. Коджаспирова [10], О. В. Семендяева [18], А. Н. Щукин [26]).

Практическая значимость исследования заключается в том, что предлагаемые методические приемы работы с видеоматериалами (социальные ролики, ролики с фрагментами из художественных фильмов) могут быть использованы учителями и студентами на уроках русского языка для формирования коммуникативных умений обучающихся среднего звена и старших классов, в процессе подготовки к итоговому собеседованию, написанию сочинения ОГЭ и ЕГЭ по русскому языку.

\section{Понятие коммуникативных умений, их классификации в психолого-педагогической литературе}

Изучение научной литературы показывает, что в современной науке существуют различные подходы к трактовке понятия коммуникативных умений и к их классификации.

Психологи рассматривают коммуникативные умения, исходя из трех сторон общения: коммуникации (обмен информацией), перцепции (восприятие людьми друг друга) и интеракции (взаимодействие) [2]. В соответствии с этим выделяют группы информационно-коммуникативных, аффективно-коммуникативных и регуляционно-коммуникативных умений.

В современной дидактике развивается направление, в рамках которого коммуникативные умения исследуются с позиции широкого использования ИКТ для межличностного опосредованного общения. Коммуникативные умения - «владение умственными и практическими действиями, направленными на установление и поддержание целесообразных взаимоотношений с людьми в процессе учебной, а затем и в профессиональной деятельности в условиях информатизации образования и общества» [20, с. 21]. Классификация включает умения в различных видах речевой деятельности и умения, связанные с ИКТ. Все умения объединяются в три группы, соответствующие информационным процессам: умения передавать, обрабатывать и хранить информацию [Там же].

В методике обучения русскому языку коммуникативными (коммуникативно-речевыми) в традиционном понимании считаются умения создавать текст. Это такие общие коммуникативные умения: раскрывать тему и основную мысль создаваемого текста; собирать и систематизировать материал для него; строить высказывание в определенной композиционной форме (речевом жанре); производить отбор языковых средств, оптимальных в данной речевой ситуации; совершенствовать написанное [19].

В рамках компетентностного и коммуникативно-деятельностного подходов к обучению русскому языку коммуникативные умения связывают с понятием коммуникативной компетенции - способности осознанно осуществлять речевую деятельность во всех ее видах. Коммуникативная компетенция предполагает речеведческие знания и коммуникативные умения в видах речевой деятельности: умение воспринимать устную и письменную речь (аудирование, чтение); умение передавать в устной и письменной форме собственные мысли грамотно, точно, логично, выразительно, с учетом конкретных условий речевого общения (говорение, письмо) [3; 6].

Таким образом, изучив различные подходы к определению коммуникативных умений, а также исходя из требований к результатам освоения основной образовательной программы, проверяемым заданиями ОГЭ и ЕГЭ по русскому языку, в качестве рабочего определения в нашем исследовании принимаем следующее: коммуникативные умения - это умения осознанно осуществлять речевую деятельность в ее рецептивных (аудирование, чтение) и продуктивных (говорение, письмо) видах, обеспечивающие успешную речевую коммуникацию, эффективное взаимодействие в ситуациях формального и неформального межличностного и межкультурного общения. В соответствии с характером речевой деятельности обозначим две группы 
коммуникативных умений: 1) умения, связанные с восприятием и адекватным пониманием информации устного и письменного сообщений; 2) умения, связанные с созданием собственных устных и письменных высказываний разных типов, жанров и стилей речи, соответствующих нормам современного русского литературного языка и нормам речевого поведения.

\section{Аудиовизуальные средства обучения, их классификации в психолого-педагогической литературе}

Педагогическая наука располагает богатым арсеналом средств обучения, среди которых особое место занимают аудиовизуальные средства, широко применяемые в процессе обучения языку в качестве самостоятельного дидактического материала и как мультимедийный компонент в учебных электронных изданиях [10; 16; 25].

Аудиовизуальные средства обучения (далее - $\mathrm{ABCO}$ ) - это учебные наглядные пособия, рассчитанные на слуховое и зрительное восприятие информации. По каналу восприятия информации АВСО подразделяются на аудитивные (фонограммы), визуальные (видеограммы), собственно аудиовизуальные (видеофонограммы) [26]. Использование таких пособий в обучении психологически обоснованно: в процессе их восприятия взаимодействуют слуховые и зрительные анализаторы, что создает наилучшие условия «для более прочного запечатления образа в памяти» $[23$, с. 15$]$. Обеспечивая образное восприятие изучаемого, АВСО реализуют принцип наглядности, сформулированный Я. А. Коменским: «...все, что только можно предоставлять для восприятия чувствами, а именно: видимое - для восприятия зрением, слышимое - слухом... Если какие-либо предметы сразу можно воспринять несколькими чувствами, пусть они сразу схватываются несколькими чувствами» [11, с. 384]. При этом великий дидакт подчеркивал особую роль наглядности в развитии речи и мышления: «...нужно учить также выражать словами все, что видишь, к чему прикасаешься... чтобы речь и мысль всегда шли бы параллельно и развивались бы, следовательно, вместе» [Там же, с. 378].

К собственно аудиовизуальным средствам обучения относятся следующие специально созданные для занятий видеоматериалы: видеофрагменты, видеофильмы, видеоуроки, видеолекции [18]. Видеоуроки и видеолекции подразделяются на документальные (записанные в обычных аудиториях), студийные (записанные в видеостудиях), постановочные (поставленные по определенному сценарию).

Видеоуроки и видеолекции стали широко использоваться в последнее время, когда школы и вузы были вынуждены перейти на дистанционное обучение из-за пандемии COVID-19. B организации образовательного процесса возросла роль интернет-ресурса «Российская электронная школа» [17]. Фонд данного интернетресурса включает полный школьный курс интерактивных уроков с короткими видеороликами с лекцией учителя, фильмотеку, видеозаписи театральных постановок, концертов, музыкальные клипы. В разделе, посвященном проекту «Киноуроки в школах России», представлены детские короткометражные художественные фильмы и методические пособия к ним для внеклассных занятий по духовно-нравственному и патриотическому воспитанию. Каждый урок посвящается одному личностному качеству или нравственному понятию, например: в начальных классах это добро - зло, дружба - вражда, героизм - трусость, патриотизм - предательство, мужество - трусость, честность - лживость и др.; в среднем звене это справедливость - пристрастность, моральный выбор - неразборчивость, рыцарство - мужланство, отзывчивость - равнодушие. Эти видеоматериалы, на наш взгляд, можно приспособить и к урокам развития речи по предмету «Русский язык».

В обучении русскому языку могут использоваться не только видеоматериалы, специально созданные для занятий, но и неучебные фильмы (их фрагменты): художественные (в том числе мультипликационные), хроникально-документальные, научно-популярные, научно-экспериментальные [9]. Кроме того, в сети Интернет доступны видеозаписи информационных, спортивных и развлекательных телепередач, социальные и рекламные ролики, которые так же можно задействовать в учебном процессе. При этом, безусловно, необходим строгий отбор видеоматериалов, главное, они должны соответствовать дидактической цели урока, возрастным особенностям школьников, иметь воспитательную ценность и включаться в урок рационально, методически грамотно.

Таким образом, разные виды АВСО, получившие в последнее время широкое применение, заключают в себе большой дидактический потенциал. Реализуя принцип наглядности в обучении, АВСО, в частности видеоматериалы, активируют различные рецепторы при восприятии информации и создают оптимальные условия для усвоения изучаемого.

\section{Основные положения по использованию комплекса методических приемов работы с видеоматериалами для формирования коммуникативных умений обучающихся}

Изучение педагогического опыта, проведенное в ходе нашего исследования, показало, что видеоматериалы, предназначенные для массовой коммуникации (неучебные), широко применяются в методике преподавания иностранных языков, в том числе РКИ. В отличие от этого, использование таких видеоматериалов на уроках русского как родного языка и русского как второго (неродного) рассмотрено недостаточно.

С учетом положительного опыта педагогов по применению АВСО в преподавании языков нами разработан комплекс методических приемов, направленный на формирование коммуникативных умений у обучающихся с использованием неучебных видеоматериалов (социальные ролики, ролики с фрагментами из художественных фильмов), в которых актуализируются нравственные концепты (милосердие, совесть, подвиг и др.). Предлагаемый комплекс методических приемов может быть использован в среднем звене и в старших классах, целесообразен при подготовке к итоговому собеседованию, написанию сочинения ОГЭ и ЕГЭ по русскому языку. 
Работа с видеоматериалом на уроке организуется в три этапа.

Первый этап - мотивационно-установочный. Основная задача данного этапа - мотивирование и подготовка обучающихся к активному восприятию информации видеоматериала. Для этого дается целевая установка на его просмотр: перед школьниками ставятся 2-3 вопроса, которые сосредоточивают их внимание на содержании видеоматериала и на которые они отвечают после показа ролика.

На данном этапе могут быть использованы следующие методические приемы, создающие ориентировочную основу для успешного восприятия:

- работа с эпиграфом к уроку; эпиграфом может служить, например, пословица или афоризм, стихотворение или отрывок из песни, в которых реализуется нравственный концепт, связанный с проблемой, поднимаемой в видеоматериале;

- ассоциативный эксперимент: в качестве стимула дается слово-концепт, каждый ученик называет свои ассоциации, и таким образом нравственный концепт активируется в их сознании;

- самостоятельное толкование обучающимися слова-концепта;

- выяснение его значения в толковом словаре;

- предваряющая беседа по теме видеоматериала, актуализирующая субъектный опыт обучающегося и нравственный концепт.

Второй этап - аналитико-синтетический. Основная задача данного этапа - активное восприятие и осмысление информации видеоматериала. Возможен повторный просмотр со стоп-кадром, способствующий глубине и точности понимания. При повторном просмотре появляется возможность сосредоточить внимание школьников на важных моментах видеоматериала, которые при первом просмотре не запечатлелись в их сознании.

На данном этапе проводится беседа по содержанию и смысловой информации видеоматериала. Беседа начинается с вопросов, заданных на предыдущем этапе, далее ставятся уточняющие и конкретизирующие вопросы. Могут быть использованы следующие методические приемы, направленные на выявление содержательной и смысловой информации видеоматериала:

- определение темы и проблемы, поднимаемой в видеоматериале;

- формулирование авторской позиции;

- выявление сюжетной линии, пересказ сюжета;

- характеристика героев (возраст, социальный статус, внешность, речь, внутреннее состояние);

- характеристика взаимоотношений героев;

- анализ конфликтной ситуации, поступков героев;

- выявление деталей, моментов, эпизодов, характеризующих героев.

Третий этап - рефлексивно-контрольный. Основная задача данного этапа - дальнейшее осмысление информации видеоматериала и формирование собственного отношения к ней.

На данном этапе организуется обсуждение, обучающиеся дают критическую оценку ситуации, поступкам героев, аргументируя свое мнение (устно и письменно). Могут использоваться следующие методические приемы:

- устное рассуждение о ситуации, поступках героев, оценка их действий;

- продолжение сюжета;

- придумывание биографии героя;

- написание отзыва, рецензии или эссе;

- составление рекламного текста к видеоматериалу;

- модификация видеодиалога;

- придумывание продолжения видеодиалога;

- интервью с героем видеоматериала;

- дискуссия по проблемам, поднятым в видеоматериале;

- групповой творческий проект: составление сценария для собственного видеоролика по проблеме просмотренного видеоматериала, составление рекламного текста к своему видеоролику, съемка видеоролика, презентация видеоролика.

Приведем в качестве примера использования видеоматериала на уроке русского языка основное содержание работы с короткометражным фильмом «Забыли!» в 9 классе (фильм Игоря Шинкевича и Марии Вие; продолжительность - 7 мин.).

Данный видеоматериал привлекается для подготовки к сочинению на тему «Что такое великодушие?». В фильме предстает история подростка, который подвергается издевательствам со стороны сверстников, но, став уверенным в себе благодаря тренеру, помогает одному из своих обидчиков в трудной ситуации. Проблематика фильма нацеливает на размышления, с одной стороны, о великодушии и взаимопомощи как нравственных основах человеческих отношений, а с другой - о жестокости и равнодушии.

На мотивационно-установочном этапе для подготовки к восприятию фильма проводится ассоциативный эксперимент: обучающимся предлагается записать свои ассоциации к слову-концепту ВЕЛИКОДУШИЕ. Обобщая свои ответы, школьники дают ему определение, далее обращаются к словарным толкованиям великодушия и отмечают, что оно проявляется многими качествами: «Великодушие - наличие высоких душевных качеств, щедрость души; благородство» [5]; «Великодушие - свойство характера, выражающееся в бескорыстной уступчивости, снисходительности, отсутствии, злопамятства, в способности жертвовать своими интересами» [21].

Целевая установка на просмотр фильма, следующая за чтением словарных определений великодушия, включает задания: внимательно смотреть; подумать, сколько частей-эпизодов можно выделить в этом фильме 
и какие проблемы в нем затрагиваются (содержательная информация - тема, проблематика, сюжет); почему фильм назван «Забыли!» и для чего он создан (смысловая информация - главная мысль, авторская позиция).

На аналитико-синтетическом этапе в ходе беседы по содержанию и смысловой информации фильма перед обучающимися ставятся следующие вопросы, наряду с заданными на предыдущем этапе:

- Каким мы видим Сашу в первом эпизоде и в эпизодах, где действие происходит в школе? (Худенький, светловолосый мальчик лет одиннадцати, с печальными глазами, разбитой губой, в запачканной одежде. Над ним постоянно издевается группа подростков.)

- Какие чувства испытывает мальчик? Какие детали характеризуют его душевное состояние? (Чувствует досаду от своего бессилия перед обидчиками, поэтому пинает бутылку на дороге, брошенную кем-то. Плачет от обиды, когда на перемене у него отбирают и рвут книгу, но никто не заступается за него. Сидит на школьной скамейке потерянный, опустошенный, идет в класс опустив голову и на уроке думает, что ему опять предстоит пережить унижение.)

- Что можно сказать о школьном вахтере и учениках, видевших, что Сашу обижают? (Вахтер оказалась черствой женщиной: услышав шум в коридоре, она отрывается от вязания, смотрит на упавшего Сашу и удаляющихся обидчиков, но ничего не предпринимает. Двое учеников, наблюдающих издалека, тоже равнодушны.)

- О каких качествах прохожего, остановившего обидчиков, говорят его поступки? (Мужчина разгоняет обидчиков, предлагает Саше помощь и приводит его в свой боксерский клуб, тренирует мальчика. В этих поступках проявляются доброта, сострадание, уважение личности ребенка. Вскоре Саша выигрывает свой первый бой на ринге; тренер гордится своим воспитанником, обнимает его и треплет по голове. Видно, что между ними уважительные и доверительные отношения и что Саша счастлив.)

- В чем проявляется великодушие Саши? (Мальчик не прошел мимо, когда увидел, как его обидчика Ваню избивают трое. Бросив рюкзак, он, не раздумывая, бежит на помощь своему обидчику. Помогая Ване подняться, подает ему руку и на его просьбу простить отвечает: «Всё, забыли!» Великодушие Саши в том, что он не затаил злобу и простил того, кто был жесток к нему.)

На рефлексивно-контрольном этапе дальнейшему осмыслению смысловой информации фильма и формированию собственного отношения к ней способствуют вопросы и задания, требующие критической оценки конфликта между персонажами и их поступков:

- Почему Саша подвергался постоянным унижениям? Почему подростки были так жестоки к нему? (Обидчики видят в нем слабого, беззащитного мальчика. Они безжалостны и не осознают последствий и опасности своих действий. Трусливы, потому что нападают на Сашу втроем-вчетвером и ретируются, когда за него заступается мужчина-спортсмен.)

- Почему вахтер и двое школьников не защитили мальчика, не помогли ему? (Возможно, равнодушие вахтера объясняется тем, что она нередко наблюдает подобные сцены и привыкла к ним, а двое школьников боятся обидчиков или просто не вмешиваются, можно сказать, что они эгоистичны.)

- Как говорил Конфуций, все люди рождаются добрыми. Подумайте: тогда почему некоторые люди становятся жестокими? (Большую роль играет окружение человека: семья, друзья, школа. Если в семье кто-то проявляет жестокость к родным, другим людям или к животным, это может закрепиться в сознании ребенка как естественная модель поведения, человек становится безжалостным, причиняет другим душевную и физическую боль.)

- Издревле установилось «золотое правило нравственности», на котором основываются многие мировые религии и философские учения: не делай другим того, чего не желаешь для себя, и поступай с другими так, как хотел бы, чтобы с тобой поступали. Обратимся в связи с этим еще раз к финальному эпизоду, когда обидчика Ваню избивают трое, а Саша бросается ему на помощь. Какую мысль транслирует этот эпизод? (Жестокость возвращается бумерангом, надо жить по законам нравственности и быть человечным.)

- Какова роль финального эпизода в сюжете фильма? Почему Саша простил? (Этот эпизод включает кульминационный момент, когда Саша прощает своего обидчика, и развязку с финалом, когда Ваня поднимает Сашин рюкзак, подает ему и они уходят вместе. Саша, добрый мальчик, прошедший через унижения, понимает внутреннее состояние избитого Вани, поэтому прощает его. Благородный и великодушный поступок Саши повлиял на то, что Ваня стал на путь переоценки своих действий.)

- В художественной литературе немало примеров проявления великодушия героев. Приведите такие примеры. (Петр Гринев из «Капитанской дочки» А. С. Пушкина, отдавший свой заячий тулуп незнакомцу Емельяну Пугачеву, попавшему в пургу; Андрей Соколов из рассказа М. А. Шолохова «Судьба человека», взявший на воспитание сироту Ванюшу; Матрена из рассказа А. И. Солженицына «Матренин двор», способная на самопожертвование; Лидия Михайловна из рассказа «Уроки французского» В. Г. Распутина, которая помогает мальчику, рискуя своей репутацией учителя.)

- Расскажите о примерах проявления великодушия в повседневной жизни.

- Итак, в каких качествах и поступках проявляется великодушие? (Великодушие проявляется во многих качествах и поступках, например: в доброте, сострадании, милосердии, чуткости, способности прощать, благородных поступках, бескорыстной помощи, самопожертвовании.)

- Составим синквейн о великодушии. (Великодушие / Добрый, милосердный / Сострадает, помогает, спасает / Качество человека, любящего людей / Добродетель.)

- Напишите дома сочинение на тему «Что такое великодушие?».

Таким образом, представленный комплекс методических приемов работы с видеоматериалами, с помощью которого моделируются речевые ситуации на уроке русского языка, стимулирует активное восприятие 
и адекватное понимание видеоматериала, монологические (устные, письменные) высказывания, диалог обучающихся с учителем и друг с другом.

\section{Заключение}

Проведенное нами исследование позволяет сделать следующие выводы.

Значимость коммуникативной компетенции в успешной социализации личности, ее самореализации обусловливает практическую цель обучения русскому языку в школе и ведущие метапредметные задачи образовательного процесса - формирование коммуникативных умений обучающихся.

В системе работы по формированию коммуникативных умений школьников особое место занимают ИКТ и АВСО, обеспечивающие реализацию дидактического принципа наглядности за счет активации различных рецепторов восприятия информации, целостности зрительно-слуховых образов, возникающих в процессе восприятия. Одним из таких эффективных АВСО являются видеоматериалы (социальные ролики, ролики с фрагментами из художественных фильмов), в которых поднимаются нравственные проблемы. Благодаря своей информативной ценности, а также яркости, выразительности средств создания образов такие видеоматериалы стимулируют речевую деятельность обучающихся.

Предлагаемый в данном исследовании комплекс методических приемов работы с видеоматериалами, используемый на мотивационно-установочном, аналитико-синтетическом и рефлексивно-контрольном этапах, создает на уроке русского языка условия для осознанного восприятия и адекватного понимания информации, развития устной и письменной речи обучающихся. Анализ содержательной и смысловой информации видеоматериала на аналитико-синтетическом этапе и разнообразные задания на основе просмотренного видеоматериала, выполняемые на рефлексивно-контрольном этапе, будут способствовать развитию интеллектуальной и эмоциональной сферы, воспитанию ценностных ориентиров, реализации творческого потенциала школьника как коммуникативной личности.

Перспективы дальнейшего исследования проблемы формирования коммуникативных умений обучающихся с применением видеоматериалов в процессе обучения русскому языку связаны с ее многоаспектностью, в частности, с рассмотрением специфики работы с разными видами видеоматериалов.

\section{Источники | References}

1. Алексеева М. П. Формирование межкультурной коммуникативной компетенции у учащихся девятого класса якутской школы на основе метода телекоммуникационных проектов (на материале английского языка): автореф. дисс. ... к. пед. н. СПб., 2005. 24 с.

2. Андреева Г. М. Социальная психология. М.: Аспект Пресс, 2014. 363 с.

3. Антонова Е. С. Методика преподавания русского языка: коммуникативно-деятельностный подход. М.: Кнорус, 2007. 464 с.

4. Афанасенко О. Б. Аудиовизуальные музыкальные средства обучения на современном уроке русского языка // Проблемы современного педагогического образования. 2018. № 60. Ч. 3. С. 36-38.

5. Большой современный толковый словарь русского языка [Электронный ресурс]. URL: https://slovar.cc/ rus/tolk/11442.html (дата обращения: 10.04.2021).

6. Воителева Т. М. Формирование коммуникативных умений и навыков учащихся 5-9 классов на уроках русского языка: дисс. .... д. пед. н. М., 2000. 339 с.

7. Выготский Л. С. Мышление и речь. М.: Директ-Медиа, 2014. 570 с.

8. Жинкин Н. И. Речь как проводник информации. М.: Наука, 1982. 159 с.

9. Ипполитова Н. А. Текст в системе обучения русскому языку в школе. М.: Флинта; Наука, 1998. 176 с.

10. Коджаспирова Г. М., Петров К. В. Технические средства обучения и методика их использования. М.: Академия, 2008. 350 с.

11. Коменский Я. А. Избранные педагогические сочинения: в 2-х т. М.: Педагогика, 1982. Т. 1. 656 с.

12. Кохендерфер Ю. В. Методика формирования иноязычной коммуникативной компетенции учащихся на основе языковых мультимедийных программ: основная и старшая школа, немецкий язык: автореф. дисс. .... к. пед. н. M., 2013. 25 c.

13. Леонтьев А. А. Язык, речь, речевая деятельность. М.: Красанд, 2010. 216 с.

14. Львов М. Р. Основы теории речи. М.: Академия, 2002. 248 с.

15. Мещеряков В. Н. Жанры школьных сочинений: теория и практика написания. М.: Флинта; Наука, 2017.328 с.

16. Разумовская М. М., Львова С. И., Капинос В. И., Львов В. В. Русский язык. 9 класс. Электронная форма учебника. М.: Дрофа; Росучебник, 2019. 247 с.

17. Российская электронная школа: образовательный портал [Электронный ресурс]. URL: https://resh.edu.ru/ (дата обращения: 10.04.2021).

18. Семендяева О. В. Аудиовизуальные технологии обучения. Кемерово: КемГУ, 2011. 156 с.

19. Система обучения сочинениям в 4-8 классах / под ред. Т. А. Ладыженской. М.: Просвещение, 1978. 292 с.

20. Тищенко В. А. Коммуникативные умения: к вопросу классификации // Казанский педагогический журнал. 2008. № 2 (56). C. 15-22. 
21. Ушаков Д. Н. Толковый словарь русского языка [Электронный ресурс]. URL: https://ushakovdictionary.ru/ word.php?wordid=4361 (дата обращения: 10.04.2021).

22. Федеральный государственный образовательный стандарт среднего общего образования [Электронный ресурс]: утв. Приказом Министерства образования и науки РФ от 17 мая 2012 г. № 413 (с изм. и доп. от: 29 декабря 2014 г., 31 декабря 2015 г., 29 июня 2017 г., 24 сентября, 11 декабря 2020 г.). URL: http://base. garant.ru/70188902/ (дата обращения: 10.04.2021).

23. Хохлова А. А. Психолого-педагогические аспекты использования аудиовизуальных средств в обучении иностранному языку // Обучение и воспитание: методики и практика. 2015. № 21. С. 13-18.

24. Хурмуз О. В. Методическая модель использования художественных фильмов при обучении русскому языку как иностранному: автореф. дисс. ... к. пед. н. М., 2019. 18 с.

25. Шарун Е. В. Использование технических средств обучения на уроках русского языка и литературы // Проблемы и перспективы развития образования: материалы VIII Междунар. науч. конф. (г. Краснодар, февраль 2016 г.). Краснодар: Новация, 2016. С. 78-82.

26. Щукин А. Н. Методика использования аудиовизуальных средств (при обучении русскому языку как иностранному). М.: Русский язык, 1981. 120 с.

\section{Информация об авторах | Author information}

RU Олесова Антонина Петровна ${ }^{1}$, к. пед. н., доц. Бурцева Дайаана Руслановна ${ }^{2}$

1,2 Северо-Восточный федеральный университет имени М.К. Аммосова, г. Якутск

EN Olesova Antonina Petrovna ${ }^{1}, \mathrm{PhD}$

Burtseva Dayaana Ruslanovna ${ }^{2}$

${ }^{1,2}$ North-Eastern Federal University named after M.K. Ammosov, Yakutsk

${ }^{1}$ olesovaantonina@mail.ru, ${ }^{2}$ dana.burseva@mail.ru

\section{Информация о статье | About this article}

Дата поступления рукописи (received): 30.04.2021; опубликовано (published): 30.06.2021.

Ключевые слова (keywords): коммуникативные умения; видеоматериалы; обучение русскому языку; комплекс методических приемов; communication skills; video materials; teaching Russian; set of methodological techniques. 